\title{
Medical Imaging Enfranchising the Patient for Better Feedback and Life-Long Wellness: From Female Pelvic Floor Control to Orgasm
}

\section{Brent Reider}

Director, Relevium Labs, Inc., 4663 Katie Lane, Oxford, Ohio, 45056, USA

Corresponding author: Brent Reider, Director, Relevium Labs, Inc., 4663 Katie Lane, Oxford, Ohio, 45056, USA. Yarlap.com

Received Date: February 02, 2020; Accepted Date: March 05, 2020; Published Date: March $08,2020$.

Citation: Reider B. (2020) Medical Imaging Enfranchising the Patient for Better Feedback and Life-Long Wellness:

From Female Pelvic Floor Control to Orgasm. Journal of Surgical Case Reports and Images, 3(3): Doi: 10.31579/2690-1897/023

Copyright: ( ) 2020. : Brent Reider. This is an open-access article distributed under the terms of the Creative Commons Attribution License, which permits unrestricted use, distribution, and reproduction in any medium, provided the original author and source are credited.

\begin{abstract}
:
Image design for healthcare instruction must be attuned to the way we learn and the formulation of our abstract knowledge. Images for a manual on how to use a medical device will differ significantly in presentation from images that are intended as guidance on how to improve corporal performance. Images for the former will rely on intentional recollection of life experiences, learned concepts and facts as tools. While not mutually exclusive, images for the latter should be designed to consciously work with procedural memory to improve bodily performance. The images in this article demonstrate this by imaging the relationship between the pelvic floor muscles, clitoris and demarking "Spots" indicated for sexual arousal. Qualitative data suggests that many individuals know little about the interactive relationship between the clitoris, pelvic floor muscles and the female orgasm. Social and educational venues are inadequate, and in some cases misleading. The use of appropriate images conveys meaning very effectively. So whether imaging for a medical condition, procedure (e.g., surgery) or device to enfranchise the patient in their wellness the individual's experience and proclivity for learning must be considered. If the images are effectively planned and executed, images can play an important role in involving the patients in their wellness. Enfranchising the patient into the process can improve patient feedback therein contributing to advancements in medical procedure and device usage.

The sequence of images is guidance based upon a woman's innate understanding of her body, so that she may move to a higher state of knowledge where her body performs better. Further, if her mind is inspired by the success, then her body could proceed beyond the achieved state repeatedly. The data confirms this performance structure. Women who score high for pelvic floor strength and coordination report high sexual functioning and genital perception.
\end{abstract}

Key Words: a spot; clitoral gland; clitoral bulb; clitoris; clitourethrovaginal complex; female ejaculation; female prostate; g spot; gräfenberg spot; gushing; k spot; o spot; p spot; procedural memory; squirting; u spot; vagina; vulva; Yarlap.

\section{Introduction}

Research indicates positive sexual performance and sexual expression are closely related with overall quality of life. Emotionally, sexual activity lowers the incident of depression and stress and supports self-esteem and intimacy. Physically, sexual activity can reduce the risk of heart disease and stroke, bolster the immune system, and help manage the body posture and pain, improve sleep and can even help individuals appear more youthful. For women, sex stimulates the vagina's natural lubricant and increases blood flow to keep the genitalia tissues healthy and strong (whipple et al., 2007). Pelvic floor muscle tone improves sexual performance, sexual expression, and bladder control, and images can be highly effective tools in helping women better understand the improvement of their bodily performance.

A sequence of images to incite arousal is guidance that must follow a woman's inherent understanding of her body. The images will differ than ones that would be used for the use of a medical device. Data reveals women who score high for pelvic floor strength and coordination report high sexual functioning and genital perception (Cacciari et al, 2017), but it suggests that many women know little about the interactive relationship between the clitoris, pelvic floor muscles and the female orgasm. The images in this article demonstrate clitourethrovaginal relationship by imaging the relationship between the pelvic floor muscles, clitoris and demarking "Spots" indicated for sexual arousal. If her mind is inspired by the success, then her body could proceed beyond the achieved state repeatedly.

\section{Background}

The muscles of the female pelvic floor are inside the pelvis and run along the floor of the abdominal cavity creating the pelvic and urogenital diaphragm. The primary function of the pelvic floor muscles, including the pubococcygeus muscle, is postural. They play an essential role in the dynamic stability of the musculoskeletal structure, working with the muscles of the spine, lower back and thighs to move the weight of the upper body to our heals (Pel et al., 2008). and they hold our visceral organs in their correct natural position (vagina, urethra, and the anus) (Kegel \& Powell, 1950; Peters, 2000). As such, pelvic muscle tone affects continence (Dumoulin et al., 2014; Pandey et al., 2019). Importantly, the pelvic floor muscles play a critical role in childbirth (Hilde et al., 2013), sexual expression and sexual performance (Whipple et al, 2007: Gianotten et al., 2007), including the eurythmic pelvic muscle contractions experienced during orgasm (Bartlik et al. 2010). 
The orgasm in the human female is a variable. The pleasure centers that provoke the orgasm and the following muscle reactions appear to depend on the type of stimulation, routing of the stimuli, muscle tone, and include the significant differences in vaginal anatomy that exists among women (Jannini et al., 2014). The shear variety in non-genital orgasms, those incited by imagination and/or stimulation running throughout the body (Komisaruk \& Whipple, 1998), including nipples, lips, mouth, anus, rectum, prostate, other body parts and even on phantom limbs (Komisaruk \& Whipple, 2011), indicates the orgasm is not intromission specific. Indeed, the reflexive muscle contraction-release sequence of the human female may be as layered and complex as the theories surrounding them (Levin \& Wagner, 1982), from contractions (Masters \& Johnson 1966; Fisher 1973; Hite, 1973), to a physiological excitatory response capable of inciting a meditative-like state (e.g., like floating on a cloud) (Davidson, 1980). Furthermore, women who experience multiple orgasms do so because their brains continue to receive signals from the genitals after orgasm and because the nerve pathways from the clitoris to the brain differ from those from the vagina to the brain (Komisaruk \& Whipple, 1994; Komisaruk \& Whipple, 1995), perhaps resulting in different perceptions to stimulation (Komisaruk et al., 1972). Simply, sexual intercourse is far from the exclusive pathway to female orgasm (Lloyd, 2005), and no definitive explanations for what triggers orgasm for the human female have been offered (Meston, 2004). Conditions for the female orgasm and features for orgasmic intensity can be trust and security (Singer $\&$ Singer, 1978; Fox et al., 1970). Since these conditions are difficult to represent in art and problematic to reproduce in the laboratory they are not in the preview of this manuscript nor intimated in the images presented in this work.

Dr. Kegel (pronounced: Kay-gl) observed "sexual feeling within the vagina is closely related to muscle tone, and can be improved through muscle education and resistive exercise (Kegel, 1952)." A relationship between muscle tone and the female orgasm is proven by measuring the pelvic muscle strength of women who experience female ejaculation (Perry \& Whipple, 1981) - an ancient normal and pleasurable phenomenon for some women (female ejaculate differs in chemistry and scent from urine) (Korda et al, 2010; Zaviacic, 1999; Belzer et al, 1984). While stimulation of the clitoris, directly or indirectly, is the sole noncontroversial effective trigger of female orgasm (Jannini, 2012), the measurement of muscle tone to incite orgasm suggests other trigger points, including the "A" Spot and "G" Spot - the latter named (by Dr. B. Whipple) for Dr. E. Gräfenberg who first documented the sensitive site and suggested two possible separate reflexive pathways involved in the orgasm. The pubococeygeus muscle of the pelvic floor receives its innervation from the pudendal nerve (which also serves the clitoris), while the third of the pubococeygeus as well as the bladder and uterus are served by the pelvic nerve (Perry \& Whipple 1981). Peripheral serotonin may also regulate the sensory threshold during genital stimulation (Marson, 2017). Other sensitive areas are acknowledged, like the "A" Spot, "K" Spot, "P" Spot, "O" Spot and "U" Spot, but reliable technique for arousal at any spot appears to diminish as distance from the clitourethrovaginal complex. The clitoral gland is the only visible part of an extensive clitourethrovaginal complex that bifurcates twice as its structure runs along the pelvic floor; first the corpus cavernosum (each branch extending toward the nearest hip) and then at the clitoral bulb (surrounding the vagina on three sides, close but perhaps not touching the wall of the vagina's cervix) (Reider, 2016). Indeed some researchers regard "G" Spot not a distinct anatomical entity but as a functional unit in arousal as the clitourethrovaginal complex.

Studies suggest approximately $10 \%$ to $33 \%$ of women ejaculate prostatic fluid when aroused (e.g., $0.3 \mathrm{~m} \mathrm{~L}$ to $150 \mathrm{~mL} ; 60 \mathrm{ml}$ thought to be the most common volume) (Wimpissinger et al., 2013). It is difficult to ascertain how many women ejaculate, in part because women are often chastened for "Squirting" because the phenomenon it either thought to be disproportionate vaginal lubrication or female urinary incontinence (Pastor \& Chmel, 2018; Jackman, 1979). Loss of urinary control is often assumed because it is estimated that approximately half of all women experience some loss of pelvic floor muscle tone from non-use, injury or strain. The loss of tone leading to female urinary incontinence includes many normal lifetime activities like childbirth, muscle strain from heavy lifting (e.g., women working in warehouses) and repetitive impact from sports (e.g., running or horseback riding) (Beck et al., 1991). Incontinence symptoms are rarely reported by women because the outcomes are intensely personal and often prompt emotional burdens of shame and embarrassment (Newman et al., 2009; Bedretdinova et al., 2016), as well as low self-esteem and it may diminish sexual activity (Thakar \& Stanton, 2002). Abstinence from sexual activity may only make the situation worse, so it is best women see professional diagnosis that includes a sample of the fluid (ejaculate tests may show creatinine, uric acid, and prostatic-specific antigen) (Salama et al., 2015). Fortunately, pelvic floor muscle re-education can treat female urinary incontinence (FDA, 2015; Newman et al., 2009) and indications suggest improved pelvic floor muscle tone has positive effect in the treatment of organ prolapse $(\mathrm{B} \phi$, 2006). Consequently, some women take measures to mitigate their ejaculatory response. A reported measure is to limit the intake of fluids, conflating the perception that the ejaculatory response is female urinary incontinence. Ejaculation can return if desired by the woman and encouraged by the partner (Tollison \& Adams, 1979).

Pelvic floor muscle training, including muscle re-education following non-use, injury or strain, universally referred to as Kegel exercises, changes muscle morphology by increasing the cross-sectional area, improves neuromuscular function by increasing the number of activated motor neurons and their frequency of excitation, and therein improves the muscles ability to contract and relax with effective control (DiNublie, 1991). Consequently, pelvic floor muscles can be trained beyond structural support of the visceral organs, upper body and tightening around the urethra, the vagina, and the rectum (DeLancey, 1990; B $\varnothing$ et al., 2001). History (Korda et al, 2010; Shakespeare, 1592) and clinical data indicates that coordinated training of the pelvic floor muscles promotes improved symmetric distribution of pressure throughout the vaginal canal which results in the ability of the woman to willfully change the symmetry of the spatiotemporal pressure distribution in the vaginal canal (Cacciari et al., 2017). The ability of the woman to clench, release and sustain waveform pelvic floor muscle contractions is known across many cultures by many names, such as Pompoir, Kabazza and Yin-yang Butterfly.

Unfortunately, clinical data suggests a significant number of women find it difficult or nearly impossible to tone their pelvic floor muscles with patient-initiated Kegel exercises (Bump et al., 1991). As with any exercise, pelvic floor exercises must be properly performed. To overcome this limitation and significantly increase patient compliance, a medical device can be used to transmit a mild electronic impulse to the pelvic floor muscles. These mild impulses instruct the muscles to work and rest safely 
with clinically proven results. The muscle toning technology is often termed AutoKegel ${ }^{\circledR}$ and it is not bio-feedback technology. Bio-feedback devices measure self-initiated muscle action and if the wrong muscles are being used in exercise, bio-feedback will still measure muscle action.

\section{Measures for Subject Effective Images}

In a recent study of women looking at an image of a vulva, $71 \%$ could identify the clitoral bulb. But only slightly more than half were able to the labia $(57 \%)$ or the vaginal opening $(55 \%)$. Less than half could find the urethra $(45 \%)$. Similarly, many women wonder if their genitalia look "normal." There really is no normal and there is a wide range of appearances in a healthy vulva. Half the women did not realize their vagina was self-cleaning and a third (33\%) thought it should be washed on a daily basis, not realizing the vagina contains a large amount of good bacteria that keeps the area healthy. Washing inside the vagina - even just with water - damages the natural balance of bacteria and is highly likely to lead to infections (Waldersee, 2019).

Women who have accurate perception of their genitalia and understand sexual function have much better sexual performance and sexual expression than women who do not. The clitoral gland can be identified by approximately $71 \%$ of the female population. However, few understand the clitoral gland is the visible part of the organ, which runs along the pelvic floor muscles. Moving front to back, the clitoral gland meets the clitoral corpus cavernosum which bifurcates with each branch extending toward the nearest hip. Then comes the clitoral bulb close but perhaps not touching the wall of the vagina's cervix. The Clitoral bulb surrounds the vagina on three sides - a " $U$ " shape that can be wide open at the top or extending around the vaginal opening as if to close the top of the "U" so it is more "O" like and very near the anus (the anus passes through the pelvic floor muscles). The entire clitoral organ, not just the visible part, is the sole noncontroversial effective trigger of female orgasm. Hence, the close proximity of the different organs in the clitourethrovaginal complex demonstrates their effective interaction to sexual arousal in the woman and the recognition of identified point of arousal along the entire complex.

Nearly $51 \%$ of women indicate stimulation of the "G" Spot is an effective means of arousal. The "G"- spot is near the female prostate. Not all women appear to have the gland(s) that produces the seminal fluid found in ejaculate or the Skene's glands, which may emit the ejaculate located near the urethra. Proximity to the urethra and differences in individual anatomy may be cause for different reports on female ejaculation. Yet while, the percentage of the population that experience female ejaculation is difficult to ascertain, women who report their "squirting" find it extremely pleasurable (Wimpissinger et al., 2013). Overall, women's knowledge of their vaginal lubrication and ejaculate, $44 \%$ did not know the origin of their fluid emissions during orgasm, and $23 \%$ described the urethra as the source while $17 \%$ identified the vagina as the source of ejaculation (Wimpissinger et al., 2013). Regarding body mass index, parity, marital status, partner count, and sexual orientation, no statistically significant differences were detected between the women studied (Ellibeş Kaya \& Çalışkan, 2018).

A number of other "Spots" lie across the clitourethrovaginal complex where direct stimulation is reported for arousal. The Posterior Fornix or "P" Spot, as it is often called - is located across from the "G" Spot on the anterior of the vaginal wall. Interestingly, the further the "spots" are from the clitoris, uniformity in location and reliability for arousal seems to diminish. $11 \%$ of women respond to stimulation of the "A" Spot. $8 \%$ report corporeal sensitivity to stimulation of the "O" Spot (Tedesco, 2015).

Gentle indirect massage of the clitoris appears to be effective. $12 \%$ of women use their pelvic floor muscle contraction and release sequences to climax (Tedesco, 2015). External massage of the clitoris appears to be effective at both the "U" Spot in the vulva below the clitoris above the urethrae ("U" for proximity to the urethrae) and the "K"-Spot - (aka "Kundalini") along the perineum. Perhaps response to the latter varies with the anterior shape of the clitoral bulb as it surrounds the circular wall of the vaginal entrance (more open like a " $U$ " or more closed like an "O"). Indications suggest the clitourethrovaginal complex is as robust as it is universally sensitive. Even if there is an anatomical change to the female genitalia (e.g., clitorectomy) it maintains its ability to respond to stimulation for orgasmic response (Berg \& Denison, 2011).

Many of the respondents in our study, 1,662 data points tracked over seven months, were careful to articulate their subjective viewpoint on their sexual function and genital perception. Indications suggest that the women whom participated in our study (using our medical device) are proactive about their health, are well educated (though not all formally) and their responses suggest personality traits of agreeableness (Graziano \& Tobin, 2009) and conscientiousness (Roberts et al., 2009). We found women that have good genital perception and an accurate understanding of their organs sexual function reported good sexual performance and sexual expression. This is concordant with other studies. Virtually all women in our study were eager to have accurate information on their bodies so they could take an active role in their pelvic floor wellbeing and muscle control, including improving their sexual performance and expression. It was intent shared across all age groups, from collegiate women to octogenarians married since seventeen years of age. Also, pelvic floor muscle control was the intent for married women, women actively dating and women not planning intimacy with another person. In this regard, if a complex function like the female orgasm is the hallmark of adaptation, there must be a purpose for the clitoris running along the pelvic floor and with the clitoral shaft readily accessible from outside the body for effective non-intromission stimulation (Reider, 2016). Perhaps then, the complex function of the female orgasm is wellness.

Universally there was interest in the clitoris and vagina as a functional unit in arousal as the clitourethrovaginal complex and embraces the " $G$ " Spot as identified by Perry and Whipple (Jannini et al., 2012). Respondents put great value in images to help them understand their pelvic health. As lay-persons, they cannot see inside or understand formal medical diagrams, but they fell it and have an intuitive understanding of function. They need more information to make their situation(s) better.

\section{Formulting Effective Images}

The way we learn and the formulation of our abstract knowledge is determined by our body (Piaget, 1971). Epistemologically, procedural memory is embodied and helps people performing certain tasks without conscious awareness of the previous experiences. Explicit memory refers to the conscious, intentional recollection of life experiences, learned concepts and information (e.g., facts) (Ullman, 2004). The difference may be compared to one's knowing how to ride a bicycle and one's explaining to someone else how to ride." While not mutually exclusive, instructions and images for a medical device are generally episodic (i.e., to achieve a set task effectively). Indeed, facts themselves are tools and evolve (i.e., 
what we know as facts today may be different in the future as we know more). Whereas the images in this article are designed to work with a woman's procedural memory; starting from an innate understanding of her body, moving to a higher state of knowledge using the information here expressed with images to where her body performs more than it did before (i.e., better) and again proceeding from the achieved state to a superior one. The data confirms this performance structure because women who score high for pelvic floor strength and coordination report high sexual functioning and genital perception (Cacciari et al., 2017).

Most woman will have an innate procedural memory sense of her body's drive for sexual arousal. Stimulation to orgasm is highly varied and orgasm is not intromission specific. While orgasm is not universal among human females (at least $10 \%$ of women never report having achieved orgasm) (Wallen \& Lloyd, 2011), women are capable of experiencing orgasm before their menses and long after menarche. Without the intent of becoming pregnant, many women strive to achieve orgasm (Lloyd, 2006). The data bears this out. Most women know the location of their clitoris (the primary effective trigger of female orgasm) (Jannini et al., 2012) followed by the vagina and popularly recognized "Spots" for arousal - generally near the clitourethrovaginal complex. An image of the clitoris can be expressed in a number of ways.

It is proposed that life size three dimensional models of individual organs might help women understand their bodies. One such project uses to scale three dimensional images of the clitoris to explain the size and shape of the organ. It can reproduce a three dimensional model from a three dimensional printer (Russo, 2017). However, a three dimensional model in itself does not show the organ in its position or help the lay-person understand size and location. These limitations can be overcome with two dimensional design. Plus, a series of two dimensional images can be used to anchor the organs to an easily understood reference point on the exterior of the body, like the vulva, for the lay-person. A large number cannot even identify the organ's location on the external part of the body (e.g. only half could identify the vaginal opening in an image of the vulva). To aid the lay-person, the parts of the vulva can be illustrated as if viewed from the outside, then in a series of drawings moving inward to specific points as illustrated in the series of images in this article.

Qualitative data suggest that many women in the target audience find medical jargon perplexing and medical images equally disengaging. Biophilic design choices, including color, appear to boost the activity of the parasympathetic nervous system, thereby decreasing stress levels and encouraging a general sense of well-being (Tsunetsugu et al., 2007). Colors can define spatial relationships. Perhaps biophilic design choices may even help comprehension because humans are extremely adept at building a framework of understanding suggested in an abstract image (Piaget, 1973; Peterson, 1999). The way we register color is in part a cultural preconception. For example we will associate the color red with blood or muscle. Colors have an instinctive psychological resonance (Wiggins, 2016). The way we actually see color is important in their use as a tool. Retinal cones, which register color are most concentrated at the center of the eye and wain towards the outer edges. So for maximum effect, active colors (yellows, reds, and oranges) should be placed in the center or where creativity and socialization is a desired emphasis. The less bright colors (dark green, dark blue, dark brown) are ideally placed at the edges (Sharpe, 1974). Also, mentally registering color requires a significant amount of neuroprocessing. Color is effective in patient gaming therapy for that reason (McGonigal, 2015). It can help make the therapy/learning more fully engaging because it demands to much mental focus. Expertise in medical gaming of the author of this article is fully concordant with the data (Reider, 2019). The use of color in medical images and diagrams is not prohibitive for women because only a small percentage of women are colorblind (approximate $0.5 \%$ of all females).

Like the application of color, the layout be attuned to the audience. The final product is a document for women who are literate, interested in pelvic wellness, conscientious and generally un-familiar with medical terminology. A majority will read either English (79\%), or a Romance language (18\%). Their eyes will instinctively scan the page left to right so the "F" Style eye scan page layout is most effective (Nielsen, 2006). If one wants the reader to read the text first, then predominantly, the text should appear on the left and the image(s) to the right. If the final document were a call to action in electronic media (e.g., sales promotion), the page layout would be in a " $Z$ " pattern (Cao, 2015) with the image to the margin.

As you look at the images, perhaps ask yourself if the human female orgasm were primarily reproductive, would not the female orgasm be more intromission-dependent and therein the structure of the clitoris more anatomically mission-focused (e.g., inside the vagina)?

Jung saw the mind/body/feelings (or what we call the psyche), as all working together (Jung, 1981). Images help us construct a map to our dreams so that perhaps in a woman's sexual function we can become the best our dreams suggest. These images, presented in series, are examples of art designed to engage the way our mind learns to help women undertake a life time of purposeful improvement of their body's performance to a level of performance they choose. 


\section{External Female Genitalia}

- Clitoral Bulb. It is located in the vulva above the urethra. It varies in size and it may be covered with a hood or exposed.

- Urethra. Uren's exit from the bladder out the body.

- Labia. These asymmetrical folds of skin, the majora and minora protect the sensitive tissues of the vulva. Among women the labia will vary in shape and color.

- Vaginal Opening. The vagina is self-cleaning and contains a large amount of good bacteria - the kind that keeps the area healthy. Douching, unless directed by a physician, can upset this balance.

- Wash your external genital area. During regular baths or showers, use a very small amount of mild, unscented soap and lots of water to gently wash the area.

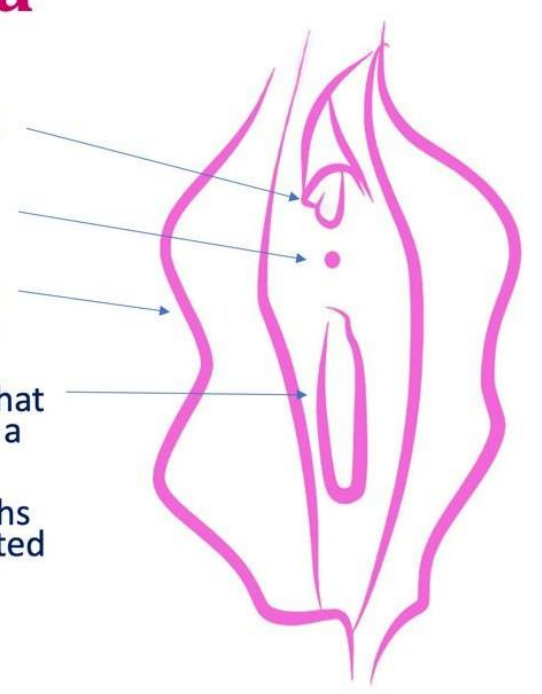

\section{Inside the External Genitalia}

- Uterus (purple, Oval). The uterus protects and nurtures the baby. The entrance of the uterus protrudes partway into the vagina.

- Vagina (purple, tube). The vagina is an elastic, muscular canal with a soft, flexible lining that provides lubrication and sensation. The vagina receives the penis during sexual intercourse It is the pathway for the baby during childbirth and menstrual flow.

- Urethra (yellow, tube). Uren's exit from the bladder to outside the body.

- Clitoris (pink). It starts at the bulb in the vulva and runs along the pelvic floor to the vagina's base. The clitoris branches twice as it runs along the pelvic floor: by the urethra (each branch extending toward the nearest hip), and then at the clitoral bulb where it partially rings the vagina's base.

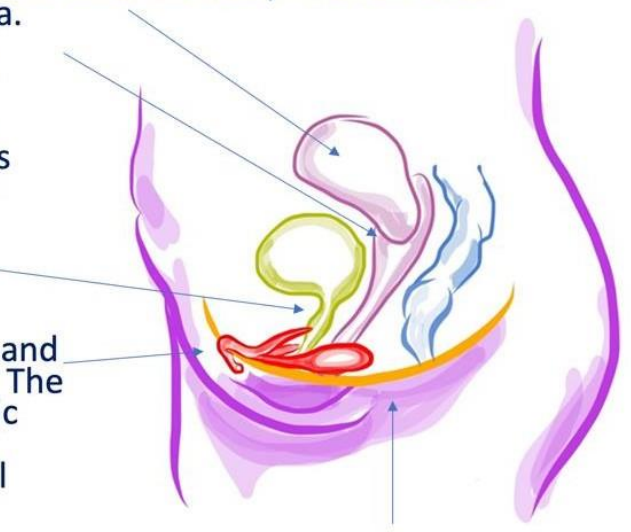

- Pelvic Floor Muscles (orange). Pelvic floor muscles lie across the base of the pelvis supporting the visceral organs and the body's alignment. Tone is essential to good bladder, bowel and sexual function. 


\section{The Pelvic Floor Muscles}

- Urethra. Pelvic floor muscles support the bladder and work with the muscle of the bladder to maintain urinary control.

- Vaginal Opening. Pelvic floor muscles work with the muscle of the bladder to maintain urinary control. These muscles contract and release for improved sexual performance and sexual experience.

- Anus. Pelvic floor muscles support the bowel and work with the muscle of the rectum to maintain fecal control.

- Posture. Pelvic floor muscles work with the muscle of the lower back, abdomen and thighs to support your spine and to properly move the weight of your body through your pelvis to your heals.

- Female Orgasm. Tone of the pelvic floor correlates to sexual function and the eurythmic contractions of arousal.

\section{Erogenous Zones - It's Personal}

- Clitoris - The bulb is visible in the vulva, but sensory response seems to run all along the clitoris at locations in and outside the body.

- "U" Spot - In the vulva below the clitoris above the urethrae ("U" for proximity to the urethrae).

- “G” Spot - (aka Gräfenberg) Many women report an erogenous zone about the size of a coin an inch inside the top front of the vagina.

- "A" Spot - Anterior Fornix (aka "Epicenter").

- "P" Spot-Posterior Fornix back wall of the vagina - opposite the " $G$ "- Spot.

- "O" Spot - Behind the "P" Spot.

- "K"-Spot - (aka "Kundalini") Along the perineum.

Variations in anatomy can be significant \& proximity to the clitoris increases response

\section{Figure. 4 Erogenous Zones - It's Personal}

\section{Conclusion}

Image design for lay-person instruction must be attuned to the way we learn and the formulation of our abstract knowledge. Therefore, images for a manual on how to use a medical device will differ significantly in presentation from images that are intended as guidance on how to improve bodily performance. Images for the former will rely on intentional recollection of life experiences, learned concepts and facts as tools. While not mutually exclusive, images for the latter should be designed to consciously work with procedural memory to improve bodily performance. The images in this article demonstrate this by imaging the relationship between the pelvic floor muscles, clitoris and demarking "Spots" indicated for sexual arousal. The sequence of images is guidance based upon a woman's innate understanding of her body, so that she may move to a higher state of knowledge where her body performs better. Further, if her mind is inspired by the success, then her body could 
proceed beyond the achieved state repeatedly. The data confirms this performance structure. Women who score high for pelvic floor strength and coordination report high sexual functioning and genital perception.

Images design to engage the patient can be used to enfranchising the patient into the well-ness process and can improve patient feedback contributing to advancements in medical device usage and medical procedures. Consequently, a patient appropriate image is not necessarily anatomically precise. I believe patient involvement is significantly enhanced with images that are designed taking into account the individual's experience and proclivity for learning.

\section{References}

1. Bartlik, B., Kolzet, J., Ahmad, N., Parveen, T. \& Alvi, S. (2010). Female sexual health. In Legato, M. (Ed.). Principles of Gender-Specific Medicine, 400-407

2. Beck, R., McCormick, S. \& Nordstrom, L. (1991). A 25-year with 519 anterior colporrhaphy procedures. Obstetrics \& Gynecology, 78, 1011-1018.

3. Berg, R. \& Denison, E. (2011). Does female genital mutilation/cutting (FGM/C) affect women's sexual functioning? A systematic review of the sexual consequences FGM/C. Sexual Research and Social Policy, 9(1), 41-56.

4. Bedretdinova, D., Fritel, X., Panjo, H. \& Ringa, V. (2016). Prevalence of female urinary incontinence in the general population according to different definitions and study designs. European Urology, 69, 256-264.

5. Bø, K. (2006). Can pelvic floor muscle training prevent and treat pelvic organ prolapse? Acta Obstetricia et Gynecologica Scandinavica, 85, 263-268.

6. Bø, K., Lillea ${ }^{\circ}$, F., Talseth, T. \& Hedlund, H. (2001). Dynamic MRI of pelvic floor muscles in an upright sitting position. Neurourology and Urodynamics, 20, 167-174.

7. Bump, R., Hurt, W., Fantl, J. \& Wyman, J. (1991). Assessment of Kegel pelvic muscle exercise performance after brief verbal instruction. American Journal of Obstetrics and Gynecology, 165(2), 322-329.

8. Cao, J. (2015). Web ui design for the human eye: content patterns \& typography.

9. Cacciari, L., Passaro, A., Amorim, A. \& Sacci, I. (2017). High special resolution pressure distribution of the vaginal canal in Pomoir practitioners: a biomedical approach for assessing the pelvic floor. Clinical Biomechanics, 47, 53-60.

10. Davidson, J. (1980). The psychobiology of sexual experience. In Davidson, J. \& Davidson, R. (Eds.), The psychobiology of consciousness, 271-332.

11. DeLancey J. (1990). Functional anatomy of the female lower urinary tract and pelvic floor. Ciba Foundation Symposium, 151, 57-76.

12. DiNublie, N. (1991). Strength training. Clinical Journal of Sports Medicine, 10, 33-62.

13. Dumoulin, C., Hay-Smith, E. \& Mac Habée-Séguin, G. (2014). Pelvic floor muscle training versus no treatment, or inactive control treatments, for urinary incontinence in women. Cochrane Database Systems Review, 14(5), CD005654.

14. Ellibeş Kaya, A. \& Çalışkan, E. (2018). Women self-reported g-spot existence and relation with sexual function and genital perception. Turkish Journal of Obstetrics and Gynecology, 15(3), 182-187.

15. Fisher S. (1973). The Female Orgasm: Psychology, Physiology, Fantasy.

16. Food \& Drug Administration. (2015). Department of Health \& Human Services, USA, Part 21 of the Code of Federal Regulations 801 Subpart C \& D, Class II Devices: Neuromuscular electrostimulation device Yarlap $^{\circledR}$ cleared for the treatment of female urinary incontinence and the reeducation of the female pelvic floor.

17. Fox, C., Wolf, H. \& Bakers, J. (1970). Measurement of intravaginal and intrauterine pressures during human coitus by radio-telemetry. Journal of Reproductive Fertility, 22, 243-251.

18. Gianotten, W., Whipple, B. \& Owens, A. (2007). Sexual activity is the cornerstone of quality of life: an update of the health benefits of sexual expression. In Tepper, M. \& Owens, A. (Eds.), Sexual Health, 1 1, 28-42

19. Graziano, W. \& Tobin, R. (2009). Agreeableness. In Leary, M. \& Hoyle, R. (Eds.), Handbook of individual differences in social behavior, 46-61.

20. Hilde, G., Stær-Jensen, J., Siafarkas, F., Engh, M., Braekken, I. $\& \mathrm{~B} \varnothing, \mathrm{K}$. (2013). Impact of childbirth and mode of delivery on vaginal resting pressure and on pelvic floor muscle strength and endurance. American Journal of Obstetrics \& Gynecology, 208(1), 50.e1-50.e7.

21. Hite S. (1973). The Hite Report. New York, NY: Macmillan Press.

22. Jackman, L. (1979). Excessive vaginal lubrication. Medical Aspects of Human Sexuality, 13, 119-120.

23. Jannini, A., Buisson, O., \& Rubio-Casillas, A. (2014). Beyond the g-spot: clitourethrovaginal complex in the female orgasm. Nature Reviews Urology, 11, 531-538.

24. Jannini, E., Rubio-Casillas, A., Whipple, B, Buisson, O., Komisaruk, B.R. \& Brody, S. (2012). Female orgasm(s): one two or several. Journal of Sexual Medicine, 9(957), 956-965.

25. Jung, C. (1981) Development of personality. The collected works of C.G. Jung (R. Hull Trans.), Vol. 17, 189

26. Kegel, A., (1952). Sexual functions of the pubococeygeus muscle. Western Journal of Surgery, Obstetrics, and Gynecology, 60, 521-524, (a).

27. Kegel A \& Powell T. (1950). The physiologic treatment of urinary stress incontinence. Journal of Urology, 63, 808-813.

28. Komisaruk, B., Alder, N., \& Hutchison, J. (1972). Genital sensory field: enlargement by estrogen treatment in female rats. Science, 178, 1295-1298.

29. Komisaruk, B., \& Whipple, B. (1994). Complete Spinal cord injury does not block perceptual responses to genital selfstimulation in women. Society for NeuroScience Abstracts, 20, 961.

30. Komisaruk, B. \& Whipple, B. (1995). The suppression of pain by genital stimulation in females. Annual Review of Sex Research, 6, 151-186.

31. Komisaruk, B. \& Whipple, B. (1998). Love as a sensory stimulation: Physiological effect of its deprivation and expression. Psychoneuroendocrinology, 23, 927-944.

32. Komisaruk, B. \& Whipple, B (2011). Non-genital orgasms. Sexual and Relationship Therapy, 26(4), 356-368. 
33. Komsiaruk, B., Whipple, B., Nasserzadeh, S. \& Beyer-Flores, C. (2010). The orgasm answer guide.

34. Korda, J., Goldstein, S \& Sommer, F. (2010). The history of female ejaculation. Journal of Sexual Medicine, 7(5), 19651975.

35. Levin, R. \& Wagner, G. (1982). Orgasmic women in the laboratory-quantitative studies on duration, intensity, latency and vaginal blood flow. Archives of Sexual Behavior, 14(5), 439-449.

36. Lloyd, E. (2005). The case of the female orgasm: bias in the science of evolution.

37. Marson, L., Giamberardino, M., Costantini, R., Czakanski, R. \& Wesselmann U. (2017). Female Sexual function: the role of animal models in assessing female sexual dysfunction. Sexual Medicine Reviews, 1(2), 108-122.

38. Masters W. \& Johnson V. (1966). Human Sexual Response. Boston, MA: Little Brown.

39. McGonigal, J. (2015). Super better: a revolutionary approach to getting stronger, happier, braver and more resilient powered by the science of games.

40. Meston, C., Levin, R., Sipski, M., Hull, E. \& Heiman, J. (2004). Women's Orgasm. Annual Review of Sex Research, 15, 173257.

41. Newman, D., Ee, C., Gordon, D., et al. (2009). Continence promotion, education and primary prevention. Incontinence. Proceedings from the 4th International Consultation on Incontinence, 1643-64.

42. Nielsen, J. (2006). F-shaped pattern for reading web content.

43. Pandey D., Maturi C., Dhakar B., Jain, G. \& Kyalakond, K. (2019). Interventions and quality of life in stress urinary incontinence. Gynecology and Minimally Invasive Therapy, 8(3), 106-112.

44. Pastor, Z. \& Chmel, R. (2018). Differential diagnostics of female "sexual" fluids: a narrative review. International Urogynecology Journal, 29, 621-629.

45. Pel, J., Spoor, C., Pool-Goudzwaard, A., Hoek van Dijke, G. \& Snijders, C. (2008). Biomechanical analysis of reducing sacroiliac joint shear load by optimization of pelvic muscle and ligament forces. Annals of Biomedical Engineering, 36(3), 415-424.

46. Perry, J. \& Whipple B. (1981). Pelvic muscle strength of female ejaculators. Journal of Sex Research, 17, 22-39.

47. Peters W. (2000). Anatomy of female pelvic support and continence. In Lentz, G. (Ed.). Urogynecology, 13-24.

48. Peterson, J. (1999). Maps of meaning: the architecture of belief. New York, NY: Routledge.

49. Piaget, J. (1971). Biology and knowledge: an essay on the relations between organic regulations and cognitive processes. (B. Weaver Trans.). Chicago, Il. University of Chicago Press.

50. Piaget, J. (1973). To Understand Is To Invent. (Roberts, G. Trans.), 20.

51. Reider, B. (2016). Role of pelvic floor muscles in female orgasmic response. Journal of Women's Health, Issues and Care, 5:6.
52. Reider, B. (2019) US Patent 10,307,589. International Patents Pending. Oxford, Ohio, USA.

53. Roberts, B., Jackson, J., Fayard, J., Edmonds, G., Meints, J. (2009). Conscientiousness. In M. R. Leary \& R. H. Hoyle (Eds.), Handbook of individual differences in social behavior, 369-381

54. Russo, N. (2017). The still-misunderstood shape of the clitoris: can $3 \mathrm{~d}$ printed model of the organ change views on female sexuality? Yes and no. an object lesson.

55. Salama, S., Boitrelle, F., Gauquelin, A., Malagrida, L., Thiounn, N., \& Desvaux, P. (2015). Nature and origin of "squirting" in female sexuality. Journal of Sexual Medicine, 12, 661-666.

56. Shakespeare, W. (1592). Venus and Adonis. Line 234. Venus offering to Adonis (Stray lower, where the pleasant fountains lie).

57. Sharpe, D. T. (1974). The psychology of color and design. Chicago, IL: Nelson-Hall Co.

58. Singer, J. \& Singer, I. (1978). Types of female orgasm. In J. LoPiccolo \& L. LoPiccolo (Eds.), Handbook of Sex Therapy, 175-186

59. Tedesco, T. (March, 2015). 4 Places that exciter her more than the g-spot. Men's Health.

60. Thakar, R. \& Stanton, S. (2002). Management of genital prolapse. BMJ. 324(7348), 1258-1262.

61. Tollison, C. \& Adams, H. (1979). Sexual disorders: treatment, theory, and research. New York, NY: Gardner Press.

62. Tsunetsugu, Y., Miyazaki, Y. \& Sato, H. (2007). Physiological effects in humans induced by the visual stimulation of room interiors with different wood quantities. Journal of Wood Science, 53, 11-16.

63. Ullman MT. (2004). Contributions of memory circuits to language: the declarative/procedural model. Cognition, 92(12), 231-270

64. Waldersee, V. (2019, March 8). Half of Brits don't know where the vagina is - and it's not just the men. In: Health Medicine \& Beauty.

65. Wallen, K., \& Lloyd, E. (2011). Female sexual arousal: genital anatomy and orgasm in intercourse. Hormones and Behavior, 59(5), 782.

66. Whipple, B., Knowles, J. \& Davis, J. (2007). The health benefits of sexual expression. In Tepper M. \& Owens, A. (Eds.), Sexual Health, 1, 1-11, 17-28.

67. Wiggins, C. (2016, March 11). Vincent van Gogh: the colour and vitality of his works| NationalGallery,London.

68. Wimpissinger, F., Springer, C. \& Stackl, W. (2013). International online survey: female ejaculation has a positive impact on women's and their partners' sexual lives. BJU International, 112(2), E177-185. 